\title{
ENSAIOS DE VARIEDADES DE GIRASSOL
}

\author{
O. Ferreira de Sousa, V. Canecchio Filho e Eduardo Abramides, engenheiros agró- \\ nomos da Seç̧ão de Oleaginosas do Instituto Agronômico.
}

\section{1 - INTRODUÇÃO}

O cultivo do girassol (Helianthus annuus L.) feito em grande escala nos países em que constitui a mais importante fonte de óleo alimentício, não tem despertado interêsse entre nós, tendo mesmo sido infrutíferas as tentativas no sentido de fomentar a sua produção. Tratando-se, porém, de uma planta que se adapta perfeitamente às condições ecológicas de São Paulo, com rendimentos que variam em tôrno de 1.500 quilos de sementes por hectare, resolveu-se executar um programa de trabalho com o objetivo de se colhêr informações sôbre o comportamento de algumas variedades em diferentes regiōes do Estado.

Os ensaios foram iniciados em 1944/45 com as variedades que na coleção se mostraram mais produtivas. Tendo em vista, porém, a grande desuniformidade observada entre as plantas, em tôdas as variedades, com relação ao porte, época de florescimento e de maturação, diâmetro dos capítulos, coloração das sementes, o que desaconselhava o seu prosseguimento, resolveu-se eliminar todo o material existente, com exceção da variedade Riscado n. ${ }^{\circ}$ 1, a única uniforme (2).

Para o desenvolvimento do programa elaborado foi providenciada, por intermédio da Secção de Introdução de Plantas, a introdução de 50 novas variedades oriundas dos principais centros que trabalham com o girassol. As observaçбes preliminares indicaram aquelas mais promissoras e que foram incluídas nos ensaios cujos resultados constituem objeto dêste trabalho $(\mathbf{I}, \mathbf{2})$.

\section{2 - ENSAIOS REALIZADOS}

Distribuídos por três séries, oito ensaios foram instalados, nos anos agrícolas de 1946/47, 1947/48 e 1948/49, nas estações experimentais de Ribeirão Prêto (ensaios n. ${ }^{\circ} \mathrm{s} 1,4$ e 6), Pindorama (ensaios n. ${ }^{\circ} \mathrm{s} 2$ e 7 ), e Mococa (ensaios n. ${ }^{\circ}$ s 3, 5 e 8). As variedades estudadas procedem da Estação Experimental de Rio Caçador, Santa Catarina, n. ${ }^{\circ} \mathrm{s} 41$ a 45 e 59 a 62 ; Estação Experimental de Pergamino, Argentina, $n .^{\circ} \mathrm{s} 46,47,48$ e 49 ; Instituto Fitotecnico La Estanzuela, Uruguai, n. ${ }^{\circ} \mathrm{s}$ 52, 54, 55, 56 e 57 e do Instituto de Ecologia do Rio de Janeiro, n. ${ }^{\circ}$ s 64 e 65 . As variedades $n .{ }^{\circ} \mathrm{s} 87$ e 90 foram recebidas da Escola Superior de Agricultura "Luís de Queiroz", de Piracicaba, e a de n. ${ }^{\circ}$ 97, da Universidade de Oxford, Inglaterra. 


\section{1 - PRIMEIRA SÉRIE DE ENSAIOS - 1946/47}

O delineamento adotado para os ensaios foi do tipo fatorial, com quatro repetiçóes, canteiros de quatro fileiras, de $10 \mathrm{~m}$ de comprimento e distâncias de $80 \mathrm{~cm}$ entre fileiras e $40 \mathrm{~cm}$ entre covas, de acôrdo, aliás, com resultados experimentais já obtidos (3). Para o estudo dos resultados foi considerada apenas a produção das fileiras internas de cada canteiro. Entre as variedades utilizadas, em número de vinte, foi incluída a de $n .^{\circ} 1$, Riscado, da antiga coleção, que serviu de testemunha.

$O$ ensaio n. ${ }^{\circ}$, instalado a 9 de novembro, apresentou boa germinação. $\mathrm{O}$ início do florescimento ocorreu aos 55 dias, nas variedades números 46 , 47 e 48, e aos 70 dias, nas demais, procedendo-se à colheita, em fins de fevereiro, 100 dias após a germinação. Observou-se um ataque de lagarta (Closyne Saundersii DBL \& Hew), bastante prejudicial à produção.

No ensaio n. ${ }^{\circ}$, semeado na primeira quinzena de outubro, a germinação, em todos os canteiros, foi prejudicada pela falta de umidade. Não obstante processou-se normalmente o desenvolvimento das plantas, oferecendo colheitas satisfatórias.

$O$ ensaio n..$^{\circ}$, semeado também nos primeiros dias de outubro, teve bom desenvolvimento. A colheita foi efetuada aos 103 dias após o plantio, nas variedades $n .^{\circ} \mathrm{s} 46,47,48$ e 54 e aos 124 dias nas demais, sendo boas as produções.

A análise estatística do conjunto dos dados obtidos nos três ensaios revelou diferenças significativas, figurando como melhores as variedades, Gigante da Rússia n. ${ }^{\circ}$ 64, Iínea-16 e La Estanzuela n. ${ }^{\circ} 53$, sem, entretanto, apresentarem produções mais altas que a da variedade testemunha.

\section{2 - SEGUNDA SFRIE DE ENSAIOS - 1947/48}

Neste ano foram instalados apenas dois ensaios nas estações experimentais de Ribeirão Prêto, n. ${ }^{\circ} 4$ e Mococa, n. ${ }^{\circ} 5$.

$O$ plano adotado foi o de blocos ao acaso, com quatro repetições, e as características do delineamento idênticas às do plano da primeira série. $\mathrm{O}$ número de variedades foi reduzido a 12 , e substituída a variedade número 59 pela de número 41 .

Os ensaios desta série, $\mathrm{n} .{ }^{\circ} \mathrm{s} 4$ e 5 , instalados na segunda quinzena de outubro e $1 .^{\circ}$ de novembro, respectivamente, tiveram alta percentagem de germinação efetuando-se a colheita cêrca de 125 dias após o plantio. Em ambos, o desenvolvimento geral das plantas foi bom, não ocorrendo o mesmo com as variedades Sel. Klein e Uruguaio, no ensaio $n .^{\circ} 5$, muito suscetíveis à mancha da fôlha.

O ensaio de Ribeirão Prêto teve o seu "stand" reduzido de aproximadamente $23 \%$ em virtude de um generalizado ataque de cupim o que explica a diminuição na produção estimada.

A análise estatística dos resultados dos ensaios referentes a esta série mostrou significância destacando-se sôbre as demais, as variedades Riscado, 
Quadro 1.-Produções médias colhidas nas três séries de ensaios e respectivas diferenças com relação a da variedade Riscado

\begin{tabular}{|c|c|c|c|c|c|c|}
\hline \multirow{2}{*}{ Variedades } & \multicolumn{2}{|c|}{ Primeira série } & \multicolumn{2}{|c|}{ Segunda série } & \multicolumn{2}{|c|}{ Terceira série } \\
\hline & Prod. & Dif. & Prod. & Dif. & Prod. & Dif. \\
\hline & $k g / h a$ & $k g / h a$ & leglha & $k g / h a$ & $k g / h a$ & $k g / h a$ \\
\hline$\frac{1}{5} 7$ - Riscado & $\begin{array}{l}1.300 \\
1.250\end{array}$ & -50 & $\begin{array}{l}2.000 \\
1.890\end{array}$ & -110 & 1.390 & $-\ldots$ \\
\hline $\begin{array}{l}53 \\
89\end{array}$ - La Estanzuela & 1.210 & -90 & 2.020 & +20 & $\begin{array}{l}1.430 \\
1.450\end{array}$ & $\begin{array}{l}+40 \\
+60\end{array}$ \\
\hline 52 - Línea-30 .... & 1.100 & -200 & 1.870 & -130 & 1.170 & -220 \\
\hline $\begin{array}{l}64 \text { - Gigante da Rússia } \\
56 \text { 二 Línea-65 } \\
45 \text { 二 Gigante da Rússia } \\
42 \text { - Cinza } \\
88 \text { Sel. Fischer-70 }\end{array}$ & $\begin{array}{r}1.290 \\
920 \\
1.050 \\
1.080\end{array}$ & $\begin{array}{l}-10 \\
-380 \\
-250 \\
-220\end{array}$ & $\begin{array}{l}1.890 \\
1.970 \\
1.730 \\
1.580\end{array}$ & $\begin{array}{r}-110 \\
-30 \\
-270 \\
-420\end{array}$ & $\begin{array}{r}870 \\
1.180 \\
1.240 \\
1.160 \\
1.320\end{array}$ & $\begin{array}{r}-520 \\
-210 \\
-150 \\
-230 \\
-\quad 70\end{array}$ \\
\hline $\begin{array}{l}41 \text { - Rajado Claro-6 } \\
65 \text { - Uruguaio } \\
55 \text { - Lúnea-82 } \\
49 \text { - Sel. Klein } \\
87 \text { - La Estanzuela }\end{array}$ & $\begin{array}{r}820 \\
1.020 \\
1.110 \\
1.090\end{array}$ & $\begin{array}{l}-480 \\
-280 \\
-190 \\
-210\end{array}$ & $\begin{array}{l}1.660 \\
1.460 \\
1.310 \\
1.270\end{array}$ & $\begin{array}{l}-340 \\
-540 \\
-690 \\
-730\end{array}$ & 1.150 & -240 \\
\hline $\begin{array}{l}90 \text { - Sel. liseher-30 } \\
592 \text { - Prêto } \\
62\end{array}$ & $\begin{array}{r}1.040 \\
910\end{array}$ & $\begin{array}{l}-260 \\
-390\end{array}$ & & & 1.130 & 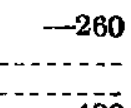 \\
\hline 97 二 Júpiter - Pardo & 900 & -400 & & & 910 & -480 \\
\hline $\begin{array}{l}43 \text { - Rajado Claro } \ldots \\
47 \text { - Saratov } \\
46 \text { - Kenglik } \\
54 \text { - Skerospheli }\end{array}$ & $\begin{array}{l}750 \\
680 \\
680 \\
510 \\
460\end{array}$ & $\begin{array}{l}-550 \\
-620 \\
-620 \\
--790 \\
-840\end{array}$ & & & & \\
\hline
\end{tabular}

Gigante da Rússia n. ${ }^{\circ} 64$ e as de procedência uruguaia, La Estanzuela n. ${ }^{\circ}$ 53, Línea-65, Línea-16 e Línea-30. No quadro 1 encontram-se os dados finais e produção.

\section{3 - TERCEIRA SERIE DE ENSAIOS - 1948/49}

Os planos dos ensaios n. ${ }^{\circ}$ s, 7 e 8 , desta $3 .^{\text {a }}$ série, obedeceram o delineamento idêntico ao da série anterior. As variedades La Estanzuela n. ${ }^{\circ}$ 87, Sel. Fischer-100, Sel. Fischer-30 e Júpiter, introduzidas em 1946, foram incluídas em substituíção às variedades Rajado Claro, Sel. Klein, Línea-82 e Uruguaio que nos ensaios precedentes se mostraram inferiores e à var. Línea-16, por falta de material suficiente.

A instalação dêstes ensaios nas localidades de Ribeirão Prêto, Pindorama e Mococa se deu na segunda quinzena de outubro procedendo-se à colheita 110 dias depois. O desenvolvimento geral das plantas ocorreu sem anormalidade, salvo no de Ribeirão Prêto, onde houve forte redução do "stand" final causado por nematóides, principalmente nas variedades $\mathbf{n} .{ }^{\circ} \mathrm{S}$ 64 e 90 . 


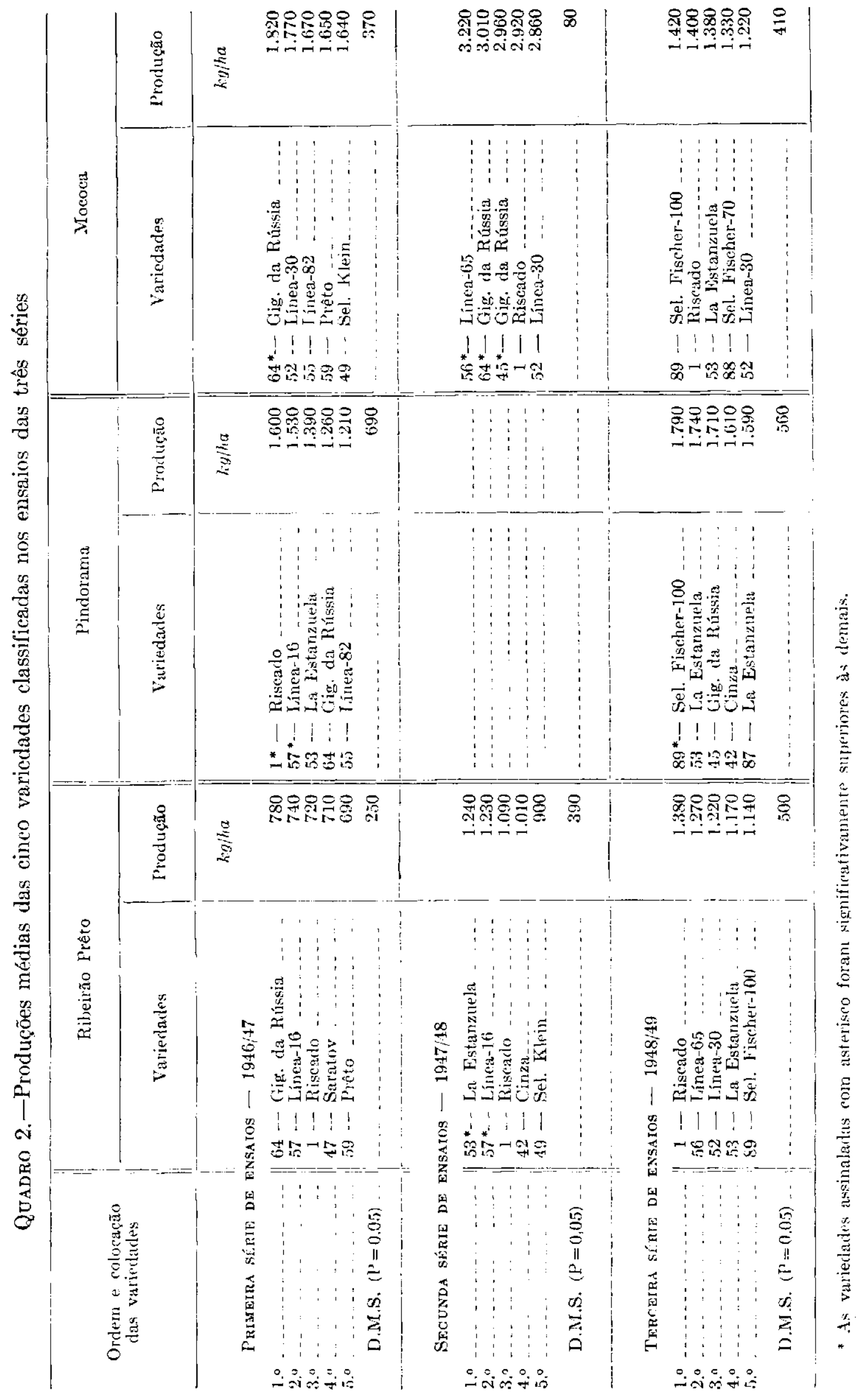


A análise dos dados referentes aos três ensaios que se encontram no quadro 1, mostrou diferenças de produção, classificando-se como melhores as variedades: Sel. Fischer-100, La Estanzuela-53, Riscado e Seleção Fischer-70.

\section{3 - COMPORTAMENTO REGIONAL DAS VARIEDADES}

Com a finalidade de se observar o comportamento regional foram reunidos no quadro 2 os números relativos às produções de cinco variedades primeiro classificadas nos ensaios. E por êsse quadro, fácil é constatar os maiores rendimentos das variedades Riscado, La Estanzuela n. ${ }^{\circ}$ 53, Línea-16, em Ribeirão Prêto e Pindorama salientando-se em Mococa, as variedades Línea-30 e Gigante da Rússia n. ${ }^{\circ}$ 64, além da Riscado. Quanto às novas variedades estudadas nos ensaios da última série aparece a Sel. Fischer-100, como a mais promissora.

\section{R E S U O}

Apesar de pouco difundida em São Paulo a cultura do girassol, resolveu-se executar um programa de ensaios regionais de variedades a fim de se determinar o seu comportamento em algumas regiões do Estado. Assim foram realizados oito ensaios, agrupados em três séries, nas estações experimentais de Ribeirão Prêto, Pindorama e Mococa, durante os anos de 1947 a 1949. A análise dos resultados indicou como mais produtivas as variedades Riscado, La Estanzuela n. ${ }^{\circ}$ 53, Línea-16, Línea-30 e Sel. Fischer-100, esta última incluida apenas nos ensaios da terceira série.

\section{S U M M A R Y}

Three series comprising eight regional trials were undertaken in order to find out the behaviour and production of some recently imported strains of sunflower (Helianthus annuus L.) in three localities of the State of São Paulo during the years 1947-1949.

These trials indicated that the following are the most promising strains : Riseado, La Estanzuela n. ${ }^{\circ}$ 53, Línea-16, Línea-30, Gigante da Rússia n.ำ 64, and Sel. Fischer-100.

\section{LITERA T U RA C I TA DA}

1. Canecchio Filho, V. e Eduardo Abramides. Ensaio sôbre variedades de girassol. Em Relatório da Secção de Oleaginosas do Instituto Agronômico 1948/49 : 27 (não publicado).

2. Ferreira de Sousa, $\mathbf{O}$. Ensaios sôbre variedades de girassol. Em Relatórios da Secção de Oleaginosas do Instituto Agronômico 1944/45 : $91 ; 1945 / 46: 126-127,1946 / 47$ : 27 e 1947/48 : 27 (nāo publicados).

3. Ferreira de Sousa, O. Ensaios sôbre espaçamento de girassol. Em Relatório da Secção de Oleaginosas do Instituto Agronômico 1944/45 : 92 (não publicado). 